\title{
Amphiphilic Ruthenium(II) Terpyridine Sensitizers with Long Alkyl Chain Substituted $\beta$-Diketonato Ligands: An Efficient Coadsorbent-Free Dye-Sensitized Solar Cells
}

\author{
Ashraful Islam, ${ }^{1,2}$ Surya Prakash Singh, ${ }^{1}$ Masatoshi Yanagida, ${ }^{1}$ \\ Mohammad Rezaul Karim, ${ }^{2}$ and Liyuan Han ${ }^{1}$ \\ ${ }^{1}$ International Center for Materials Nanoarchitectonics (MANA) and Advanced Photovoltaics Center, \\ National Institute for Materials Science (NIMS), 1-2-1 Sengen, Tsukuba, Ibaraki 305-0047, Japan \\ ${ }^{2}$ Center of Excellence for Research in Engineering Materials (CEREM), College of Engineering, King Saud University, \\ Riyadh 11421, Saudi Arabia
}

Correspondence should be addressed to Ashraful Islam, islam.ashraful@nims.go.jp

Received 16 October 2010; Accepted 3 December 2010

Academic Editor: Mohamed Sabry Abdel-Mottaleb

Copyright () 2011 Ashraful Islam et al. This is an open access article distributed under the Creative Commons Attribution License, which permits unrestricted use, distribution, and reproduction in any medium, provided the original work is properly cited.

\begin{abstract}
Three alkyl-substituted $\beta$-diketonato-ruthenium(II)-polypyridyl sensitizers with different alkyl chain lengths, [Ru(tctpy)(tfpd) (NCS)] (A1), [Ru(tctpy)(tfdd)(NCS)] (A2), and [Ru(tctpy)(tfid)(NCS)] (A3), were designed and synthesized for dye-sensitized solar cells (DSCs) to investigate the effect of bulky alkyl chain substituents on the photovoltaic performances (where tctpy $=4,4^{\prime}, 4^{\prime \prime}-$ tricarboxy-2, $2^{\prime}: ; 6^{\prime}, 2^{\prime \prime}$-terpyridine, tfpd =1,1,1-trifluoropentane-2,4-dione, tfdd = 1,1,1-trifluorodecane-2,4-dione, and tfid =1,1,1trifluoroicosane-2,4-dione). These complexes exhibit a broad metal-to-ligand charge transfer absorption band over the whole visible range extending up to $950 \mathrm{~nm}$. All complexes were examined in the presence and absence of the coadsorbent deoxycholic acid (DCA) in dye-bath solutions. These sensitizers, when anchored to nanocrystalline $\mathrm{TiO}_{2}$ films, achieve efficient sensitization to $\mathrm{TiO}_{2}$ electrodes. Under standard AM 1.5 sunlight, the complex A3 containing long alkyl chain length of $\mathrm{C}_{16}$ yielded a shortcircuit photocurrent density of $18.0 \mathrm{~mA} / \mathrm{cm}^{2}$, an open-circuit voltage of $0.64 \mathrm{~V}$, and a fill factor of 0.66 , corresponding to an overall conversion efficiency of 7.6\% in the absence of DCA. The power conversion efficiency of A1 sensitized DSCs was significantly increased upon the addition of DCA as compared to that in the absence of DCA. However, the photovoltaic performance of A3 was not dependent on DCA at all, probably due to the inherent structural nature of the A3 molecule.
\end{abstract}

\section{Introduction}

In general, dye-sensitized solar cells (DSCs) comprise a nanocrystalline titanium dioxide $\left(\mathrm{TiO}_{2}\right)$ electrode modified with a dye and fabricated on a transparent conducting oxide TCO, a platinum counter electrode, and an electrolyte solution with a dissolved iodide ion/triiodide $\left(\mathrm{I}^{-} / \mathrm{I}_{3}^{-}\right)$ redox couple between the electrodes [1-5]. Among these elements, the photosensitizer plays a vital role for the light harvesting efficiency. Many sensitizers, including organic sensitizers [6] and transition metal complexes [7-16], have been employed in DSCs. Ru(II) polypyridyl sensitized nanocrystalline $\mathrm{TiO}_{2}$ solar cells yielding solar to electric power conversion efficiency of over $11 \%$ under standard AM 1.5 condition $[13,14]$. This is because of their intense charge-transfer (CT) absorption in the whole visible range, and the absorption properties can be tuned by changing the donor-acceptor properties of the ligand in a controlled manner. Photoexcitation of the charge-transfer (CT) excited states of the adsorbed dye leads to an efficient injection of electrons into the conduction band of the $\mathrm{TiO}_{2}$.

$\mathrm{Ru}(\mathrm{II}) \quad 4,4^{\prime}, 4^{\prime \prime}$-tricarboxy-2,2' $: 6^{\prime}, 2^{\prime \prime}$-terpyridine based dyes show efficient panchromatic sensitization of nanocrystalline $\mathrm{TiO}_{2}$ solar cell that make these class of sensitizers as potential candidates for near-IR dye development [7, 9, $13,15,16]$. We have reported a series of $\mathrm{Ru}(\mathrm{II}) 4,4^{\prime}, 4^{\prime \prime}$ tricarboxy-2,2': $6^{\prime}, 2^{\prime \prime}$-terpyridine based dye containing $\beta$ diketonato ligand that efficiently sensitized nanocrystalline $\mathrm{TiO}_{2}$ over the whole visible range extending into the near IR region $[10,12,15,16]$. An important feature of 
$\beta$-diketonato ligand is its structural versatility due to presence of three substituents on the ligand. Therefore, a desired electronic environment on the metal center, improvement of light harvesting efficiency by extending $\pi$-conjugated system, and also introduction of bulky substituent to suppress dye aggregation on $\mathrm{TiO}_{2}$ surface is possible by molecular designing of the three substituents on the $\beta$-diketonato ligand.

Coadsorbents are usually added in the dye solutions to suppress aggregate formation resulting in an improved performance of DSCs through increasing both the shortcircuit photocurrent density $\left(J_{\mathrm{sc}}\right)$ and the open-circuit voltage $\left(V_{\text {oc }}\right)[10,12,13,15-23]$. Such aggregate formation has been suggested to promote unwanted intermolecular energy transfer or nonradiative decay pathways, thus reducing the electron injection efficiency. Organic dyes have been found to be more susceptible to aggregate formation compared to Ru-polypyridine based dye [1923]. Conversely, Ru-bipy ridyl based dye has been shown not to form aggregates and addition of coadsorbent in dye-bath solutions only yields a modest or no increase in photocurrents [8, 14]. Although $\mathrm{Ru}(\mathrm{II}) 4,4^{\prime}, 4^{\prime \prime}$-tricarboxy$2,2^{\prime}: 6^{\prime}, 2^{\prime \prime}$-terpyridine based panchromatic sensitizers containing NCS and/or $\beta$-diketonato ligand show potential candidates for further improvement of device efficiency, they are susceptible to aggregate formation resulting in a poor device performance without additive in dye-bath solutions $[7,9-13,15,16]$. In addition, some works showed that the power conversion efficiency of DSCs can be further improved by introducing bulky alkyl chains into the dye structure to obtain an insulating effect of dye layer on the $\mathrm{TiO}_{2}$ surface [19, 24-27]. Considering the high potentiality of efficient DSCs based on $\mathrm{Ru}(\mathrm{II})$-terpyridine dyes, a strategic structural modification of these dyes is an effective approach to improve light harvesting efficiency in the near-IR region and also suppression of aggregate formation resulting in a coadsorbent-free efficient device processing. Recently we have reported that a $\beta$-diketonato ruthenium(II)-tricarboxy$2,2^{\prime}: 6^{\prime}, 2^{\prime \prime}$-terpyridine sensitizer with extended $\pi$-conjugated system by introducing a triphenylamine substituted $\beta$-diketonato ligand shows efficient sensitization of nanocrystalline $\mathrm{TiO}_{2}$ over the whole visible range extending up to $1000 \mathrm{~nm}$ [16]. Here we report the synthesis and characterization of terpyridine-ruthenium(II) complexes with $\beta$-diketonato ligands having different substituted alkyl chain lengths 1,1,1-trifluoropentane-2,4-dione (tfpd), 1,1,1trifluorodecane-2,4-dione (tfdd), and 1,1,1-trifluoroicosane2,4-dione (tfid) and investigated their effects on DSCs performance in the presence and absence of deoxycholic acid (DCA) as a coadsorbent, with the aid of photophysical, and photoelectrochemical measurements. The molecular structures of the complexes [Ru(tctpy)(tfpd)(NCS)] (A1), $[\mathrm{Ru}(\mathrm{tctpy})(\mathrm{tfdd})(\mathrm{NCS})](\mathrm{A} 2)$, and [Ru(tctpy)(tfid)(NCS)] (A3), and DCA are shown in Figure 1.

\section{Experimental Details}

2.1. Materials. The following chemicals were purchased and used without further purification: hydrated ruthenium trichloride (from Aldrich), ammonium thiocyanate (from TCI), 1,1,1-trifluoropentane-2,4-dione (tfpd) (from Aldrich), and LH-20 Sephadex gel (from Sigma). 1,1,1trifluorodecane-2,4-dione (tfdd) [28], 1,1,1-trifluoroicosane-2,4-dione (tfid) [28] and $\mathrm{Ru}\left(\mathrm{H}_{3}\right.$ tctpy) $\mathrm{Cl}_{3}$ [11] were synthesized using the literature procedures. Complexes $[R u(t c t p y)(t f p d)(N C S)]$ (A1) and [Ru(tctpy)(tfid)(NCS)] (A3) were prepared using the literature procedure [15].

Synthesis of $[R u(t c t p y)(t f d d)(N C S)](\mathbf{A} 2)$. Using the same conditions as for complex A1, and starting from ligand 1,1,1trifluorodecane-2,4-dione (tfdd), the title compound was obtained as a dark green powder, [Ru(tctpy)(tfdd)(NCS)] (A2). Yield was 60\%: MS (ESIMS): $m / z: 249.3(\mathrm{M}-3 \mathrm{H})^{3-}$, $374.5(\mathrm{M}-2 \mathrm{H})^{2-} .{ }^{1} \mathrm{H}$ NMR $\left(300 \mathrm{MHz}, \mathrm{D}_{2} \mathrm{O}-\mathrm{NaOD}\right): \delta 8.76$ $(2 \mathrm{H}, \mathrm{s}), 8.72(2 \mathrm{H}, \mathrm{d}), 8.52(\mathrm{H}, \mathrm{d}), 8.46(\mathrm{H}, \mathrm{d}), 7.85$ $(\mathrm{H}, \mathrm{d}), 7.78(\mathrm{H}, \mathrm{d}), 5.84(0.5 \mathrm{H}, \mathrm{s}), 5.82(0.5 \mathrm{H}, \mathrm{s}), 2.53$ $(2 \mathrm{H}, \mathrm{m}), 1.55-0.80(8 \mathrm{H}, \mathrm{m}), 0.50(3 \mathrm{H}, \mathrm{m})$, Anal. Calcd for $\mathrm{C}_{29} \mathrm{H}_{28} \mathrm{~F}_{3} \mathrm{~N}_{4} \mathrm{O}_{8} \mathrm{RuS} \cdot\left(\mathrm{H}_{2} \mathrm{O}\right)_{2}$ : C, 44.27; H, 4.10; N, 7.12, found: C, $45.01 ; \mathrm{H}, 4.21 ; \mathrm{N}, 6.88$.

2.2. Analytical Measurements. UV-visible spectra were recorded on a Shimadzu UV-3101PC spectrophotometer. Steady-state emission spectra were recorded using a grating monochromator (Triax 1900) with a CCD image sensor. The redox potential of the complexes was measured using a standard three-electrode apparatus.

2.3. Preparation of $\mathrm{TiO}_{2}$ Electrode and Dye-Loading Measurements. Nanocrystalline $\mathrm{TiO}_{2}$ photoelectrodes of about $20 \mu \mathrm{m}$ thickness (area: $0.25 \mathrm{~cm}^{2}$ ) were prepared using a variation of a method reported by Nazeeruddin et al. for solar cells measurements [11]. We also prepared transparent $\mathrm{TiO}_{2}$ film of $7 \mu \mathrm{m}$ thicknesses to check the adsorption properties of the complexes on to $\mathrm{TiO}_{2}$ film using the same method. The dye-loading measurement on $\mathrm{TiO}_{2}$ films was carried out by desorbing the dye into $0.1 \mathrm{M} \mathrm{NaOH}$, solution in $\mathrm{CH}_{3} \mathrm{OH}$ and the dye load on the $\mathrm{TiO}_{2}$ film was estimated by means of an ultraviolet-visible absorption spectroscopy.

2.4. Fabrication of Dye-Sensitized Solar Cell. Two-electrode sandwich cell configurations were used for photovoltaic measurements. The dye-deposited $\mathrm{TiO}_{2}$ film was used as the working electrode and a platinum-coated conducting glass as the counter electrode. The two electrodes were separated by a surlyn spacer ( $40 \mu \mathrm{m}$ thick) and sealed up by heating the polymer frame. The electrolyte was composed of $0.6 \mathrm{M}$ dimethylpropyl-imidazolium iodide (DMPII), 0.05 $\mathrm{M} \mathrm{I}_{2}$, and $0.1 \mathrm{M}$ LiI in acetonitrile (AN).

\section{Results and Discussion}

3.1. Photophysical Properties. The absorption, emission, and electrochemical properties of complexes A1, A2, and A3 are summarized in Table 1. All the complexes show similar absorption spectra in ethanol-methanol solution as shown in Figure 2. The bands in the visible region are assigned to metal-to-ligand charge-transfer (MLCT) transitions and in the UV region to ligand $\pi-\pi^{*}$ transitions 


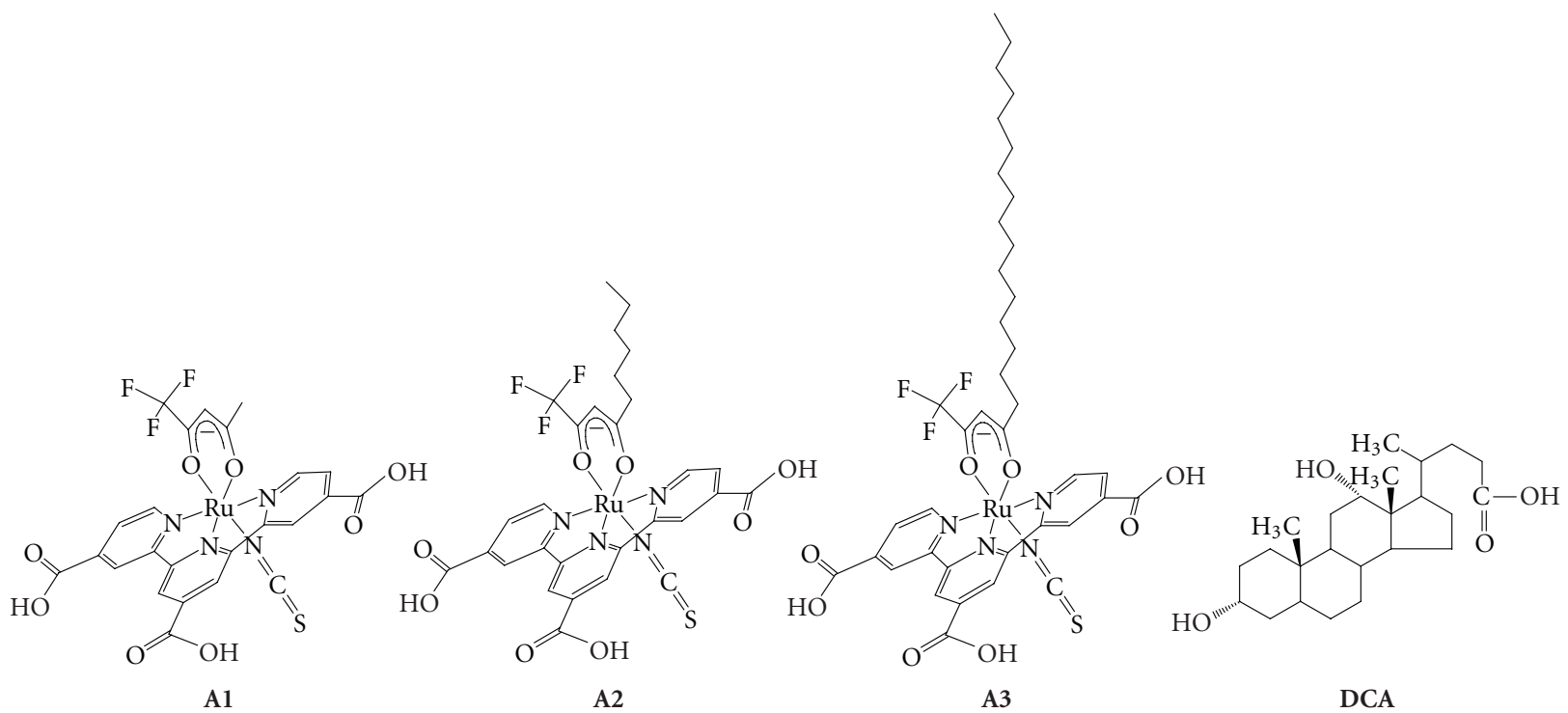

Figure 1: Molecular structures of complexes A1, A2, A3, and DCA.

TABLE 1: Absorption, luminescence, and electrochemical properties of the ruthenium complexes.

\begin{tabular}{|c|c|c|c|c|c|c|c|}
\hline \multirow{2}{*}{ Sensitizer } & \multirow{2}{*}{ Absorption, ${ }^{\mathrm{a}} \lambda_{\max } / \mathrm{nm}\left(\varepsilon / 10^{3} \mathrm{M}^{-1} \mathrm{~cm}^{-1}\right)$} & \multicolumn{2}{|c|}{ Emission $\lambda_{\max } \mathrm{b} / \mathrm{nm}$} & \multicolumn{2}{|c|}{ Emission $\tau^{\mathrm{b}} / \mathrm{ns}$} & \multirow{2}{*}{$\begin{array}{l}E\left(\mathrm{Ru}^{3+/ 2+}\right)^{\mathrm{c}} / \\
\text { versus SCE }\end{array}$} & \multirow{2}{*}{$\begin{array}{l}E^{*}\left(\mathrm{Ru}^{3+/ 2+}\right)^{\mathrm{d}} / \\
\text { versus SCE }\end{array}$} \\
\hline & & $298 \mathrm{~K}$ & $77 \mathrm{~K}$ & $298 \mathrm{~K}$ & $77 \mathrm{~K}$ & & \\
\hline A1 & $280(27.6), 331(22.7), 422(14.7), 606(7.0)$ & 940 & 905 & 16 & 160 & +0.68 & -0.90 \\
\hline A2 & $280(28.2), 331(23.1), 418(13.6), 605(7.1)$ & 945 & 900 & 15 & 214 & +0.70 & -0.95 \\
\hline A3 & $280(30.0), 331(23.6), 422(14.7), 606(7.0)$ & 950 & 910 & 16 & 152 & +0.70 & -0.95 \\
\hline
\end{tabular}

${ }^{a}$ Measured in $4: 1 \mathrm{v} / \mathrm{v}$ ethanol: methanol at room temperature.

${ }^{\mathrm{b}}$ The emission spectra and emission lifetime were obtained by exciting into the lowest MLCT band in $4: 1 \mathrm{v} / \mathrm{v}$ ethanol : methanol.

${ }^{c}$ Half-wave potentials assigned to the $\mathrm{Ru}^{3+/ 2+}$ couple for ruthenium sensitizers bound to nanocrystalline $\mathrm{TiO}_{2}$ film, measured in $0.1 \mathrm{M} \mathrm{LiClO}_{4}$ acetonitrile solution.

${ }^{\mathrm{d}}$ Calculated from $E^{*}\left(\mathrm{Ru}^{3+/ 2+}\right)=E\left(\mathrm{Ru}^{3+/ 2+}\right)-E^{0-0} ; E^{0-0}$ values were estimated from the $5 \%$ intensity level of the emission spectra at $77 \mathrm{~K}$.

of $4,4^{\prime}, 4^{\prime \prime}$-tricarboxy-2,2': $: 6^{\prime}, 2^{\prime \prime}$-terpyridine [29]. The lowenergy MLCT band maximum of complex A1 is observed at $606 \mathrm{~nm}$ with the molar extinction coefficient of about $7000 \mathrm{M}^{-1} \mathrm{~cm}^{-1}$. The emission spectra of complex A3 in ethanol-methanol mixed solvents at 77 and $298 \mathrm{~K}$ are presented in Figure 3. The luminescence data are displayed in Table 1. At 77 K, complexes A1, A2, and A3 displayed excitedstate lifetimes ranging from 152 to $214 \mathrm{~ns}$. The lifetimes decreased significantly with increasing temperature, to $15-$ $16 \mathrm{~ns}$ in fluid solution at $298 \mathrm{~K}$. The very short-lived excited state in fluid solution may be caused by efficient nonradiative decay via low-lying ligand-field excited states [30]. The excited-state lifetime of all the complexes is long enough for the process of electron injection into the conduction band of the $\mathrm{TiO}_{2}$ electrode to be efficient [31]. To be a suitable sensitizer in DSCs, the band structure of the metal complex should match the energy level of the semiconductor anode and the redox electrolyte or the hole conductor. The electrochemical data of the complexes measured in methanol solution are summarized in Table 1 . All the complexes exhibit quasireversible oxidation wave for the $\mathrm{Ru}^{3+/ 2+}$ couple ranging from +0.68 to $+0.70 \mathrm{~V}$ versus SCE. The formation of an
MLCT excited state of these complexes formally involves the oxidation of a HOMO having metal $t_{2 g}$ orbital character and reduction of a terpyridine-based LUMO.

3.2. Dye Adsorption Behavior. Figure 4 shows the absorption spectra of complexes A1, A2, and A3 adsorbed onto a nanocrystalline $7 \mu \mathrm{m}$ thick $\mathrm{TiO}_{2}$ film. All the complexes show almost similar absorption spectra on $\mathrm{TiO}_{2}$ film but the absorbance decreases with increasing alkyl chain length of the substituted $\beta$-diketonato ligands. We compare the UVvis absorption spectra for the $\mathbf{A} \mathbf{1}$ dye-loaded $\mathrm{TiO}_{2}$ films, with and without the addition of DCA during the dye-loading process. When DCA was added in the dye solution, the dyesensitized $\mathrm{TiO}_{2}$ film cografted along with DCA and showed a similar absorption spectrum. The absorbance at around $570 \mathrm{~nm}$ decreased by $18 \%$ compared with that of without DCA. The competition of DCA with the dye for binding to the $\mathrm{TiO}_{2}$ surface is responsible for the decrease in dye adsorption. The adsorbed amount of dye on the $\mathrm{TiO}_{2}$ film with and without DCA was listed in Table 2. It was noticed that the amount of dye adsorbed onto the $\mathrm{TiO}_{2}$ surface was 
TABLE 2: Adsorbed amount of dye and cell performance ${ }^{\mathrm{a}}$ of $\mathbf{A 1}, \mathbf{A 2}$, and A3 sensitizers with and without DCA.

\begin{tabular}{lcccccccc}
\hline Sensitizer & DCA $(\mathrm{mM})$ & $\mathrm{IPCE}_{\max }$ & $J_{\mathrm{sc}}\left(\mathrm{mAcm}^{-2}\right)$ & $V_{\text {oc }}(\mathrm{V})$ & $\mathrm{FF}$ & $\eta(\%)$ & $\mathrm{Dye}^{\mathrm{load}}\left(10^{-8} \mathrm{~mol} \mathrm{~cm}^{-2}\right)$ \\
\hline A1 & 0 & 67 & 15.9 & 0.53 & 0.63 & 5.31 & 11.5 \\
& 15 & 74 & 18.5 & 0.56 & 0.64 & 6.63 & 7.6 \\
\hline A2 & 0 & 69 & 17.2 & 0.57 & 0.63 & 6.18 & 9.4 \\
& 15 & 72 & 18.1 & 0.58 & 0.65 & 6.82 & 7.2 \\
\hline A3 & 0 & 72 & 18.0 & 0.64 & 0.66 & 7.60 & 7.3 \\
& 15 & 70 & 17.4 & 0.64 & 0.67 & 7.46 & 6.6 \\
\hline
\end{tabular}

${ }^{a}$ Conditions: sealed cells; coadsorbate, DCA 0 or $15 \mathrm{mM}$; photoelectrode, $\mathrm{TiO}_{2}\left(20 \mu \mathrm{m}\right.$ thickness and $\left.0.25 \mathrm{~cm}^{2}\right)$; electrolyte, $0.6 \mathrm{M}$ DMPII, $0.1 \mathrm{M}$ LiI, $0.05 \mathrm{I}_{2}$ in AN; irradiated light, AM 1.5 solar light $\left(100 \mathrm{~mW} \mathrm{~cm}^{-2}\right)$. $J_{\text {sc }}$ : short-circuit photocurrent density; $V_{\mathrm{oc}}$ : open-circuit photovoltage; FF: fill factor; $\eta$ : total power conversion efficiency; IPCE: incident photon-to-current conversion efficiency.

${ }^{\mathrm{b}}$ Surface concentration of the dye molecules on $\mathrm{TiO}_{2}$ film.

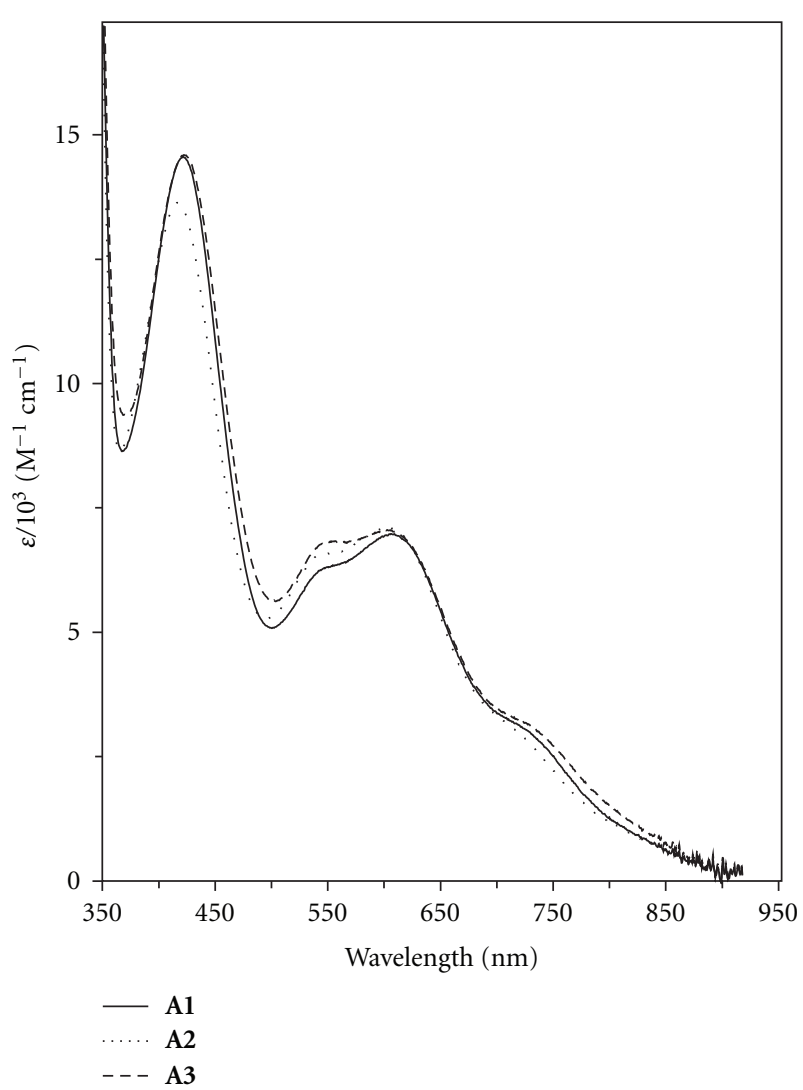

Figure 2: UV-vis absorption spectra of complexes A1, A2, and A3 in ethanol-methanol $(4: 1)$ solution.

reduced in the presence of DCA, as compared to that without DCA in the dye bath. For complex A1, the difference between the amount of dye adsorbed onto the $\mathrm{TiO}_{2}$ surface in the presence and absence of DCA in the dye bath is $34 \%$. This is maybe due to the suppression of dye aggregation in the presence of DCA. For complex A3, having long alkyl chain length, the amount of dye adsorbed onto the $\mathrm{TiO}_{2}$ surface in the absence of DCA decreases compared to that of A1. There was a small decrease in dye load when DCA was added into the dye bath. The amount of complex $\mathbf{A} \mathbf{3}$ adsorbed onto the $\mathrm{TiO}_{2}$ surface decreased by only $9 \%$ in the presence of DCA,

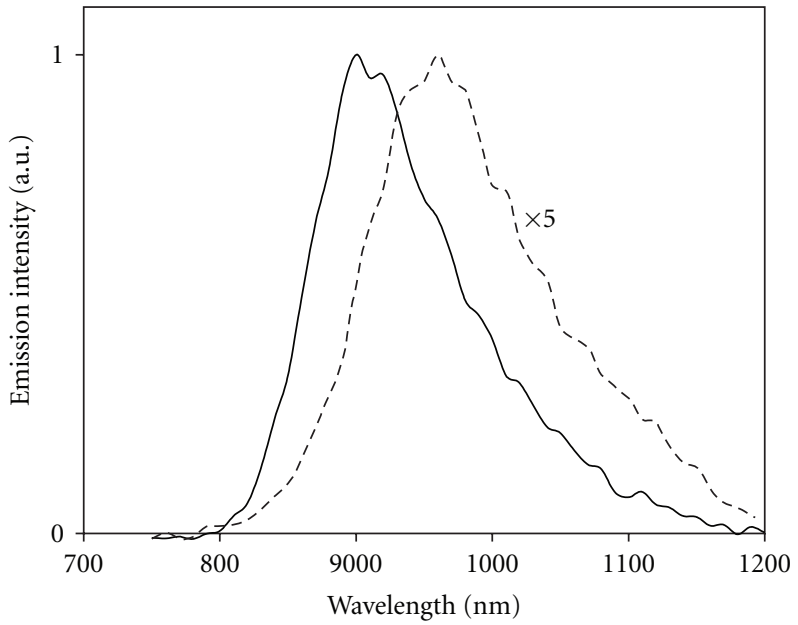

Figure 3: Emission spectra of complex A3 in ethanol-methanol $(4: 1)$ solution at $77 \mathrm{~K}(-)$ and $298 \mathrm{~K}(---)$.

whereas the complex A1 load was reduced about 34\%. The long alkyl chain present on complex $\mathbf{A} \mathbf{3}$, may be suppress the aggregate formation onto the $\mathrm{TiO}_{2}$ surface and works like DCA. It is suggested that $\mathbf{A} \mathbf{3}$ form an ordered dye layer on $\mathrm{TiO}_{2}$ surface and binds more strongly to the $\mathrm{TiO}_{2}$ surface than DCA.

3.3. Photovoltaic Properties. The photovoltaic performance of complexes A1, A2, and $\mathbf{A} 3$ on nanocrystalline $\mathrm{TiO}_{2}$ electrode was studied under standard AM 1.5 irradiation $\left(100 \mathrm{~mW} \mathrm{~cm}^{-2}\right)$ using an electrolyte with a composition of $0.6 \mathrm{M}$ dimethylpropyl-imidazolium iodide (DMPII), $0.05 \mathrm{MI}_{2}$, and $0.1 \mathrm{M}$ LiI in acetonitrile in the presence and absence of DCA in the dye bath. The short-circuit photocurrent density $\left(J_{\mathrm{sc}}\right)$, open-circuit voltage $\left(V_{\mathrm{oc}}\right)$, fill factors $(\mathrm{FF})$, and overall cell efficiencies $(\eta)$ for each dye$\mathrm{TiO}_{2}$ electrode are summarized in Table 2. Figure 5 shows the photocurrent action spectra for complexes $\mathbf{A} \mathbf{1}$ and $\mathbf{A} \mathbf{3}$ in the presence and absence of DCA, where the incident photon to current conversion efficiency (IPCE) values is plotted as a function of wavelength. All complexes achieved efficient sensitization of nanocrystalline $\mathrm{TiO}_{2}$ over the whole visible 


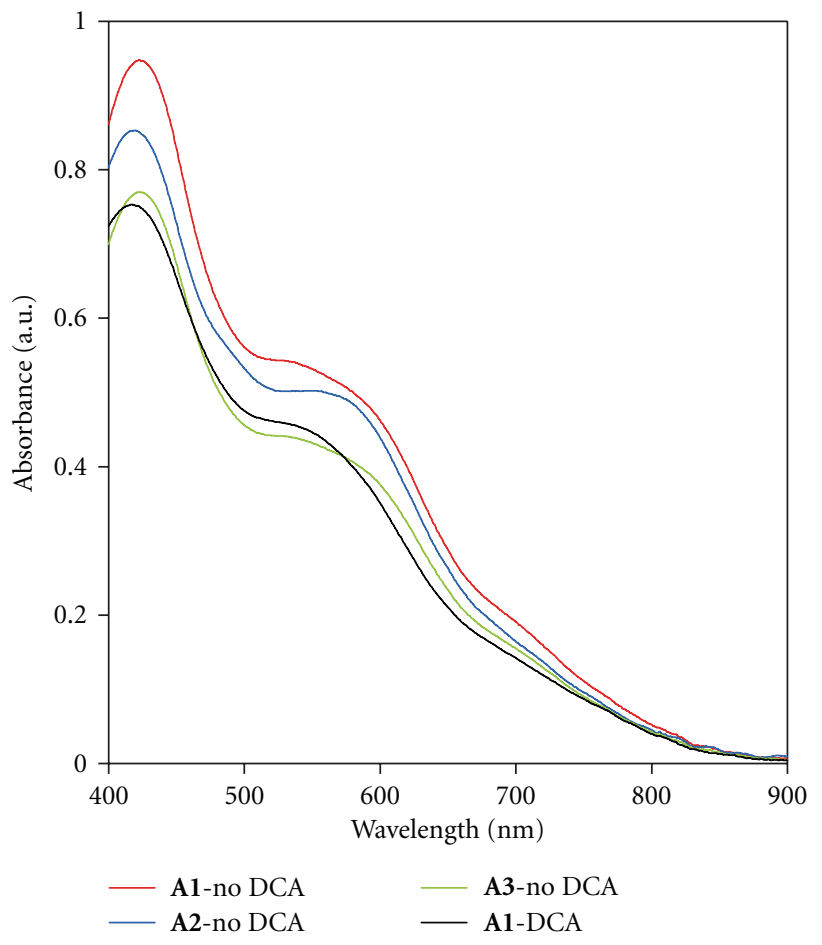

Figure 4: Absorption spectra of complexes A1, A2, and A3 adsorbed onto a nanocrystalline $7 \mu \mathrm{m}$ thick $\mathrm{TiO}_{2}$ film.

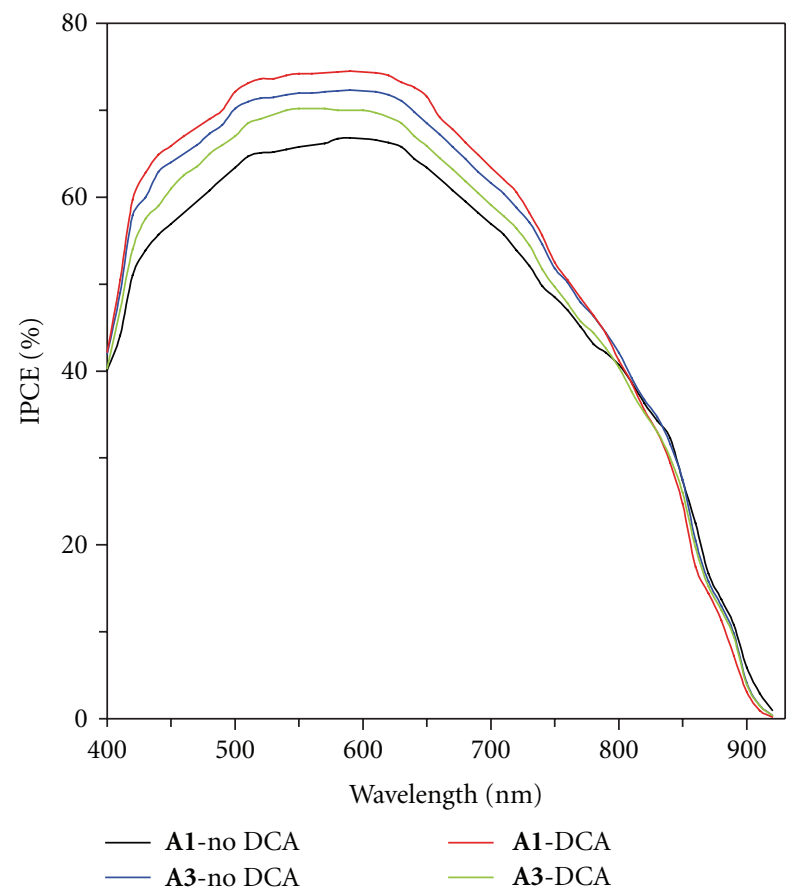

FIGURE 5: Photocurrent action spectra obtained with complexes A1 and $\mathbf{A} 3$ with and without DCA addition during the sensitization process. Incident photon-to-current conversion efficiency is plotted as a function of wavelength. A sandwich type sealed cell configuration was used to measure this spectrum. The electrolyte composition was $0.6 \mathrm{M} \mathrm{DMPII}, 0.05 \mathrm{M} \mathrm{I}_{2}$, and $0.1 \mathrm{M} \mathrm{LiI}$ in acetonitrile. range extending into the near IR region. The maximum IPCE values of complexes A1-A3 are given in Table 2.

As shown in Table 2, a solar cell containing complex A1 yielded a short-circuit photocurrent density $\left(J_{s c}\right)$ of $15.9 \mathrm{~mA} \mathrm{~cm}^{-2}$, an open-circuit photovoltage $\left(V_{\text {oc }}\right)$ of $0.53 \mathrm{~V}$, and a fill factor $(\mathrm{FF})$ of 0.63 , corresponding to an overall conversion efficiency $(\eta)$ of $5.3 \%$ in the absence of DCA. The addition of DCA gave a pronounced efficiency enhancement up to $6.6 \%$ with a short-circuit photocurrent density of $18.5 \mathrm{~mA} \mathrm{~cm}^{-2}$ and an open-circuit photovoltage of $0.56 \mathrm{~V}$. Although the amount of complex Al adsorb on the $\mathrm{TiO}_{2}$ film decreased to $34 \%$ with the addition of DCA during the dyeloading process, the values of $J_{\mathrm{sc}}, V_{\mathrm{oc}}$, and, thus, the efficiency were increased as compared to the case without DCA addition. As shown in Figure 5, complex A1 shows the IPCE value of $67 \%$ in the plateau region in the absence of DCA, and the maximum IPCE value increased up to $74 \%$ with the addition of DCA during the dye-loading process. The observed changes in $J_{s c}$ agreed well with the corresponding IPCE spectra for A1-sensitized DSCs with and without the addition of DCA. The main possible explanation is that the coadsorption of DCA prevents dye aggregation, which can cause intermolecular energy transfer and sequentially result in the excited-state quenching of the dyes [19]. As a result, the reduction of dye load on the $\mathrm{TiO}_{2}$ surface in the presence of DCA consequently results in more efficient electron injection from the excited dyes to the $\mathrm{TiO}_{2}$ conduction band [19]. A more efficient electron injection thus compensates for the less amount of dye adsorption.

It is interesting to find that A3-sensitized DSCs having a long alkyl chain, in the absence of DCA, give a high overall conversion efficiency of $7.6 \%$ with a short-circuit photocurrent density of $18.0 \mathrm{~mA} \mathrm{~cm}^{-2}$ and an open-circuit photovoltage of $0.64 \mathrm{~V}$. The photovoltaic performance of A3sensitized DSCs is higher than that of A3-sensitized DSCs with the addition of DCA during the dye-loading process. This indicates that the photovoltaic performance of bulky alkyl chain substituted sensitizer A3 was not dependent on additive DCA. It is expected that the injection of electron into the $\mathrm{TiO}_{2}$ conduction band and the recombination of electrons in the $\mathrm{TiO}_{2}$ film with the oxidized species in the redox electrolyte is unaffected in A3-sensitized DSCs with and without DCA addition. As shown in Table 2, the amount of adsorbed $\mathbf{A} 3$ on $\mathrm{TiO}_{2}$ surface with and without DCA addition is almost the same and also shows similar photovoltaic performance which suggest a selfassembly property of complex $\mathbf{A} \mathbf{3}$ due to the presence of a bulky alkyl chain substitute in the structure. A selfassembly property of the dye during the sensitization of $\mathrm{TiO}_{2}$ film is important to obtain efficient surface coverage and efficient electron injection and thus obtain high photovoltaic performance of DSCs [19]. Figure 1 showed that the A3 sensitizer contains long alkyl chain in the $\beta$-diketonato ligand which may produce surface blocking through steric hindrance, preventing the access of electrons to the redox electrolyte, which will be in favor of higher $V_{\text {oc }}$. On the other hand, this bulky alkyl group may not only facilitate the ordered molecular arrangement on the $\mathrm{TiO}_{2}$ surface but also keep dye molecules at a distance, which may suppress 
possibly intermolecular dye interaction, favoring higher $J_{\text {sc }}$ [19]. The protection by the alkyl chain is proven to be more efficient as compared to the coadsorption of DCA under the examined conditions. However, the less efficient surface protection in A1 sensitizer resulted in poor photovoltaic performance. In conclusion, higher power conversion efficiencies were obtained for DSCs based on A3 with bulky alkyl substituent due to the inherent properties of the dye molecule.

As illustrated in Figure 1, A2 sensitizer has an alkyl chain length of $\mathrm{C}_{6}$ on the $\beta$-diketonato ligand which is shorter than A3 sensitizer $\left(\mathrm{C}_{16}\right)$. Thus, an expected intermediate performance for A2-sensitized DSCs was obtained in comparison with $\mathbf{A} \mathbf{1}$ and $\mathbf{A} \mathbf{3}$ under both conditions, with and without the DCA addition. From Table 2, it is clear that the dye load of A2 dropped by about $23 \%$ due to the addition of DCA in the dye bath. However, the value of $J_{\text {sc }}$ increased with decreasing dye coverage, probably due to the same reason as mentioned for A1.

The A3 sensitizer having long alky chain substituent on the $\beta$-diketonato ligand shows the best performance in this series. Thus, this class of diketonato ruthenium complexes serves as a basis for further design of new potential sensitizers by introducing suitable substituents on the diketonato ligand to prevent surface aggregation of the sensitizer for efficient injection efficiencies and furthermore to enhance the molar extinction coefficient of the sensitizer.

\section{Conclusions}

Three panchromatic photosensitizers A1, A2, and A3 based

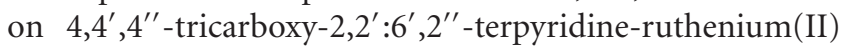
complexes with one $\beta$-diketonato chelating ligand containing different bulky alkyl chain lengths between $\mathrm{C}_{1}-$ $\mathrm{C}_{16}$ were developed and systematically characterized using electrochemical and spectroscopic methods. The complexes achieved efficient sensitization of nanocrystalline $\mathrm{TiO}_{2}$ over the whole visible range extending into the near IR region (ca. $950 \mathrm{~nm}$ ). These dyes showed gradually enhanced photovoltaic performance with increasing the alkyl chain length. The photovoltaic data of these new complexes show $7.6 \%$ power conversion efficiency under standard AM 1.5 irradiation $\left(100 \mathrm{~mW} \mathrm{~cm}^{-2}\right)$. To understand the effect of the bulky substituent on the photovoltaic performance of DSCs, we investigated the photovoltaic performances of A1-, A2-, and A3-sensitized DSCs with and without DCA addition in the dye bath. We notice that the photovoltaic performance of A3-sensitized DSCs containing bulky alkyl chain length of $\mathrm{C}_{16}$ was independent of the DCA, while the A2 bearing alkyl chains length of $\mathrm{C}_{6}$ and A1 without alkyl chain showed $10 \%$ and $24 \%$, respectively, improvement in photovoltaic performance in the presence of the DCA. Without DCA, A3-based DSCs were still superior to both $\mathbf{A} \mathbf{1}$ and $\mathbf{A} \mathbf{2}$ in the presence of DCA. This is probably due to the inherently structural nature of A3 molecule, functionalized with bulky alkyl chain substituent, which resulted in excellent photovoltaic performance.

\section{References}

[1] B. O’Regan and M. Grätzel, "A low-cost, high-efficiency solar cell based on dye-sensitized colloidal $\mathrm{TiO}_{2}$ films," Nature, vol. 353, no. 6346, pp. 737-740, 1991.

[2] A. Hagfeld and M. Grätzel, "Light-induced redox reactions in nanocrystalline systems," Chemical Reviews, vol. 95, no. 1, pp. 49-68, 1995.

[3] A. Hagfeldt and M. Grätzel, "Molecular photovoltaics," Accounts of Chemical Research, vol. 33, no. 5, pp. 269-277, 2000.

[4] M. Grätzel, "Solar energy conversion by dye-sensitized photovoltaic cells," Inorganic Chemistry, vol. 44, no. 20, pp. 68416851, 2005.

[5] M. Grätzel, "Conversion of sunlight to electric power by nanocrystalline dye-sensitized solar cells," Journal of Photochemistry and Photobiology A, vol. 164, no. 1-3, pp. 3-14, 2004.

[6] A. Mishra, M. K. R. Fischer, and P. Büuerle, "Metal-Free organic dyes for dye-Sensitized solar cells: from structure: property relationships to design rules," Angewandte Chemie, vol. 48, no. 14, pp. 2474-2499, 2009.

[7] A. Islam, H. Sugihara, and H. Arakawa, "Molecular design of ruthenium(II) polypyridyl photosensitizers for efficient nanocrystalline $\mathrm{TiO}_{2}$ solar cells," Journal of Photochemistry and Photobiology A, vol. 158, no. 2-3, pp. 131-138, 2003.

[8] A. Hagfeldt, G. Boschloo, L. Sun, L. Kloo, and H. Pettersson, "Dye-sensitized solar cells," Chemical Reviews, vol. 110, no. 11, pp. 6595-6663, 2010.

[9] T. Funaki, M. Yanagida, N. Onozawa-Komatsuzaki, K. Kasuga, Y. Kawanishi, and H. Sugihara, "Efficient panchromatic sensitization of nanocrystalline $\mathrm{TiO}_{2}$-based solar cells using 2-pyridinecarboxylate-substituted Ruthenium(II) complexes," Chemistry Letters, vol. 38, no. 1, pp. 62-63, 2009.

[10] A. Islam, F. A. Chowdhury, Y. Chiba et al., "Synthesis and characterization of new efficient tricarboxyterpyridyl $(\beta$ diketonato) ruthenium(II) sensitizers and their applications in dye-sensitized solar cells," Chemistry of Materials, vol. 18, no. 22, pp. 5178-5185, 2006.

[11] M. K. Nazeeruddin, P. Péchy, T. Renouard et al., "Engineering of efficient panchromatic sensitizers for nanocrystalline $\mathrm{TiO}_{2}$ based solar cells," Journal of the American Chemical Society, vol. 123, no. 8, pp. 1613-1624, 2001.

[12] A. Islam, F. A. Chowdhury, Y. Chiba et al., "Ruthenium(II) tricarboxyterpyridyl complex with a fluorine-substituted $\beta$ diketonato ligand for highly efficient dye-sensitized solar cells," Chemistry Letters, vol. 34, no. 3, pp. 344-345, 2005.

[13] Y. Chiba, A. Islam, Y. Watanabe, R. Komiya, N. Koide, and L. Han, "Dye-sensitized solar cells with conversion efficiency of 11.1\%," Japanese Journal of Applied Physics, Part 2, vol. 45, no. 24-28, pp. L638-L640, 2006.

[14] Q. Wang, S. Ito, M. Grätzel et al., "Characteristics of high efficiency dye-sensitized solar cells," Journal of Physical Chemistry B, vol. 110, no. 50, pp. 25210-25221, 2006.

[15] A. Islam, H. Sugihara, M. Yanagida et al., "Efficient panchromatic sensitization of nanocrystalline $\mathrm{TiO}_{2}$ films by $\beta$ diketonato ruthenium polypyridyl complexes," New Journal of Chemistry, vol. 26, no. 8, pp. 966-968, 2002.

[16] S. Gao, A. Islam, Y. Numata, and L. Han, "A $\beta$-diketonato ruthenium(II) complex with high molar extinction coefficient for panchromatic sensitization of nanocrystalline $\mathrm{TiO}_{2}$ film," Applied Physics Express, vol. 3, no. 6, Article ID 062301, 2010. 
[17] A. Morandeira, I. López-Duarte, B. O’Regan et al., “Ru(II)phthalocyanine sensitized solar cells: the influence of coadsorbents upon interfacial electron transfer kinetics," Journal of Materials Chemistry, vol. 19, no. 28, pp. 5016-5026, 2009.

[18] Z. Zhang, N. Evans, S. M. Zakeeruddin, R. HumphryBaker, and M. Grätzel, "Effects of $\omega$-guanidinoalkyl acids as coadsorbents in dye-sensitized solar cells," Journal of Physical Chemistry C, vol. 111, no. 1, pp. 398-403, 2007.

[19] X. Jiang, T. Marinado, E. Gabrielsson, D. P. Hagberg, L. Sun, and A. Hagfeldt, "Structural Modification of organic dyes for efficient coadsorbent-free dye-sensitized solar cells," Journal of Physical Chemistry C, vol. 114, no. 6, pp. 2799-2805, 2010.

[20] H. Chen, H. Huang, X. Huang et al., "High molar extinction coefficient branchlike organic dyes containing $\mathrm{Di}(p$ tolyl)phenylamine donor for dye-sensitized solar cells applications," Journal of Physical Chemistry C, vol. 114, no. 7, pp. 3280-3286, 2010.

[21] X. Ren, Q. Feng, G. Zhou, C. H. Huang, and Z. S. Wang, "Effect of cations in coadsorbate on charge recombination and conduction band edge movement in dye-sensitized solar cells," Journal of Physical Chemistry C, vol. 114, no. 15, pp. 71907195, 2010.

[22] T. Marinado, M. Hahlin, X. Jiang et al., "Surface molecular quantification and photoelectrochemical characterization of mixed organic dye and coadsorbent layers on $\mathrm{TiO}_{2}$ for dyesensitized solar cells," Journal of Physical Chemistry C, vol. 114, no. 27, pp. 11903-11910, 2010.

[23] J. H. Yum, S. J. Moon, R. Humphry-Baker et al., "Effect of coadsorbent on the photovoltaic performance of squaraine sensitized nanocrystalline solar cells," Nanotechnology, vol. 19, no. 42, Article ID 424005, 2008.

[24] S. Ito, H. Miura, S. Uchida et al., "High-conversion-efficiency organic dye-sensitized solar cells with a novel indoline dye," Chemical Communications, no. 41, pp. 5194-5196, 2008.

[25] C. Kim, H. Choi, S. Kim et al., "Molecular engineering of organic sensitizers containing p-phenylene vinylene unit for dye-sensitized solar cells," Journal of Organic Chemistry, vol. 73, no. 18, pp. 7072-7079, 2008.

[26] H. Choi, S. Kim, S. O. Kang et al., "Stepwise cosensitization of nanocrystalline $\mathrm{TiO}_{2}$ films utilizing $\mathrm{Al}_{2} \mathrm{O}_{3}$ layers in dyesensitized solar cells," Angewandte Chemie, vol. 47, no. 43, pp. 8259-8263, 2008.

[27] N. Koumura, Z. S. Wang, S. Mori, M. Miyashita, E. Suzuki, and K. Hara, "Alkyl-functionalized organic dyes for efficient molecular photovoltaics," Journal of the American Chemical Society, vol. 128, no. 44, pp. 14256-14257, 2006.

[28] J. C. Sloop, C. L. Bumgardner, and W. D. Loehle, "Synthesis of fluorinated heterocycles," Journal of Fluorine Chemistry, vol. 118, no. 1-2, pp. 135-147, 2002.

[29] A. Mamo, A. Juris, G. Calogero, and S. Campagna, "Nearinfrared luminescence at room temperature of two new osmium(II) terdentate polypyridine complexes," Chemical Communications, no. 10, pp. 1225-1226, 1996.

[30] A. Islam, N. Ikeda, A. Yoshimura, and T. Ohno, "Nonradiative transition of phosphorescent charge-transfer states of ruthenium(II)-to-2,2'-biquinoline and ruthenium(II)-to$2,2^{\prime}: 6^{\prime}, 2^{\prime \prime}$-terpyridine in the solid state," Inorganic Chemistry, vol. 37, no. 12, pp. 3093-3098, 1998.

[31] Y. Tachibana, S. A. Haque, I. P. Mercer, J. R. Durrant, and D. R. Klug, "Electron injection and recombination in dye sensitized nanocrystalline titanium dioxide films: a comparison of ruthenium bipyridyl and porphyrin sensitizer dyes," Journal of Physical Chemistry B, vol. 104, no. 6, pp. 1198-1205, 2000. 


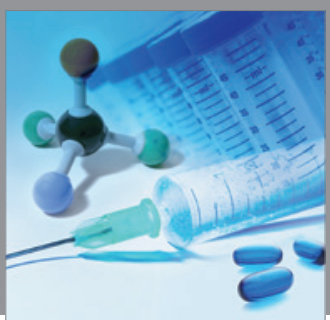

International Journal of

Medicinal Chemistry

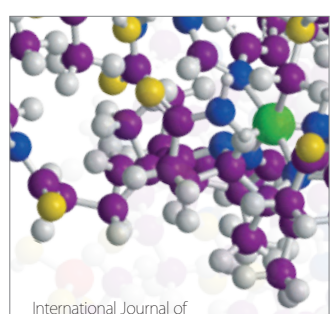

Carbohydrate Chemistry

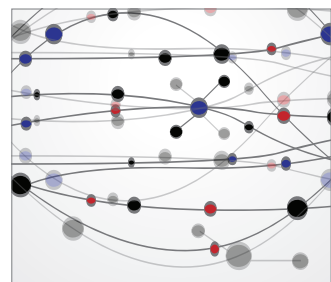

The Scientific World Journal
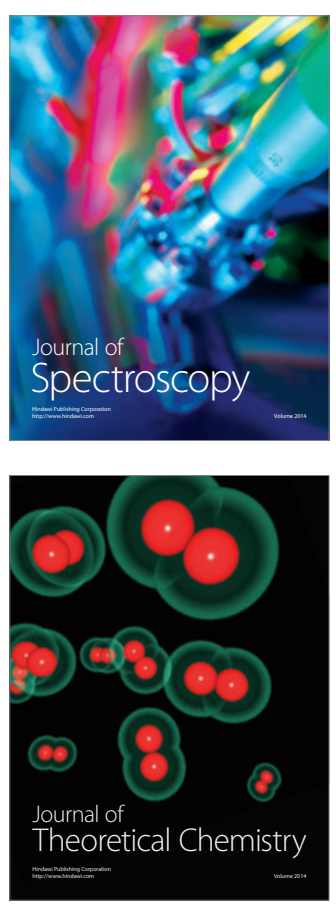
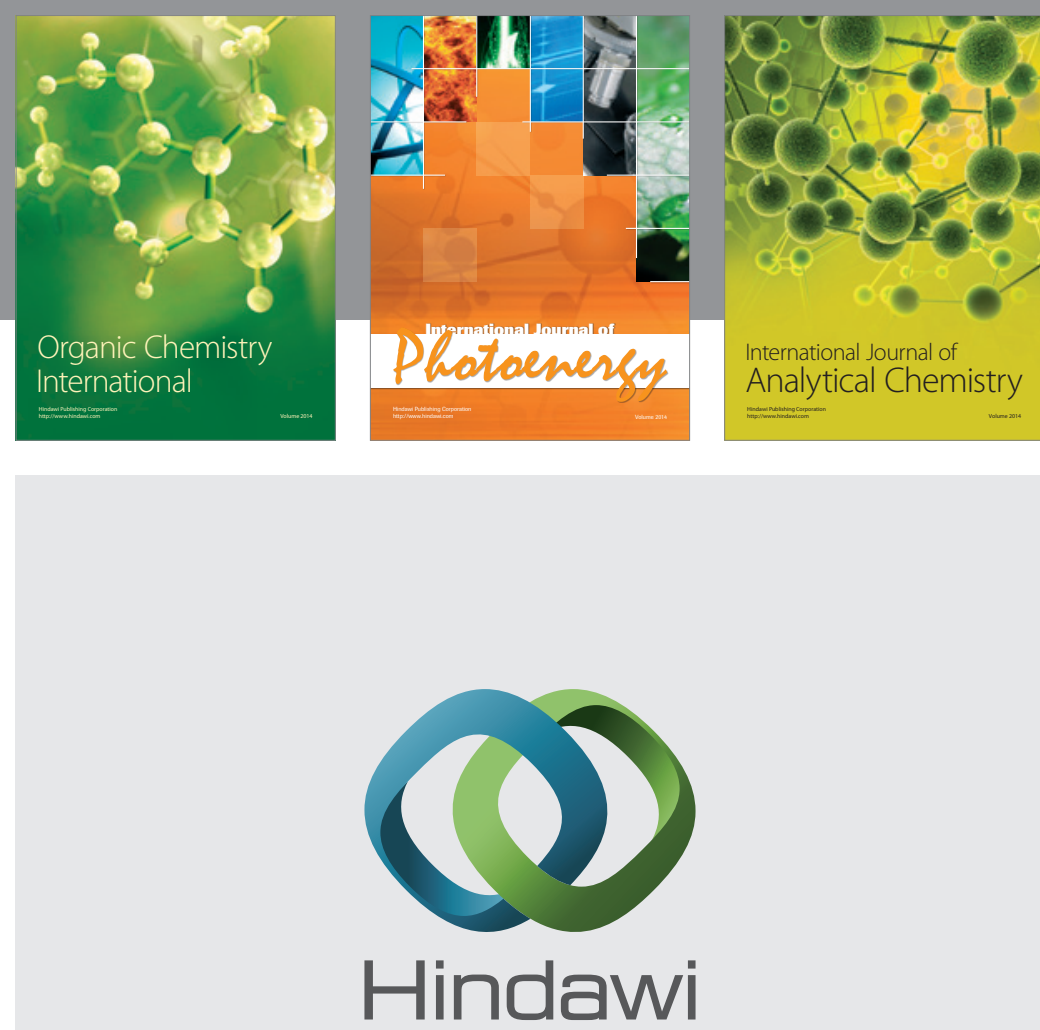

Submit your manuscripts at

http://www.hindawi.com
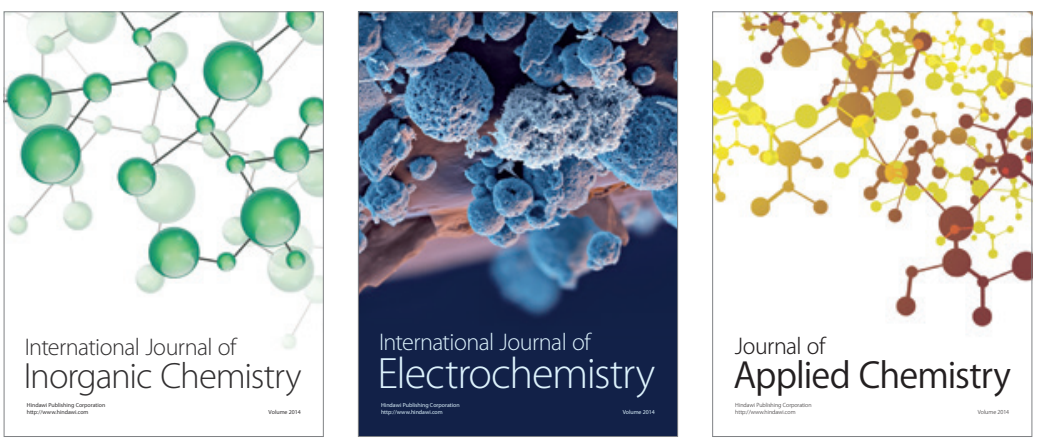

Journal of

Applied Chemistry
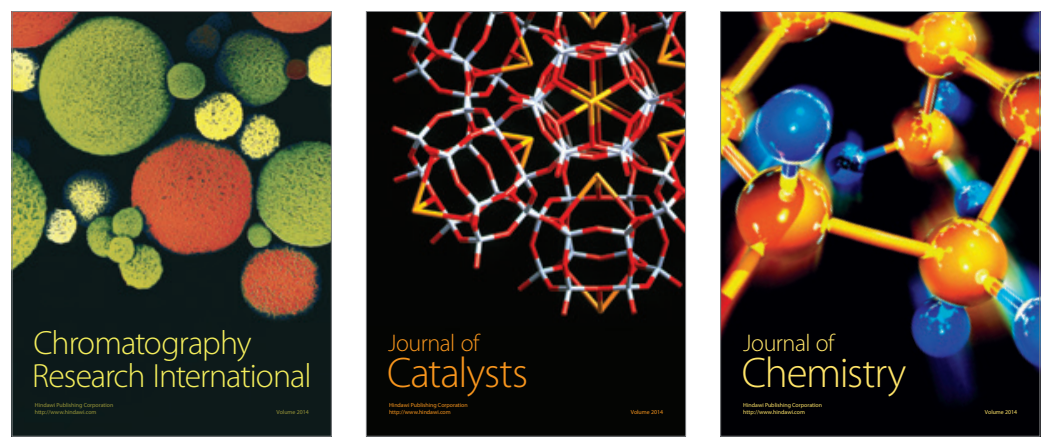
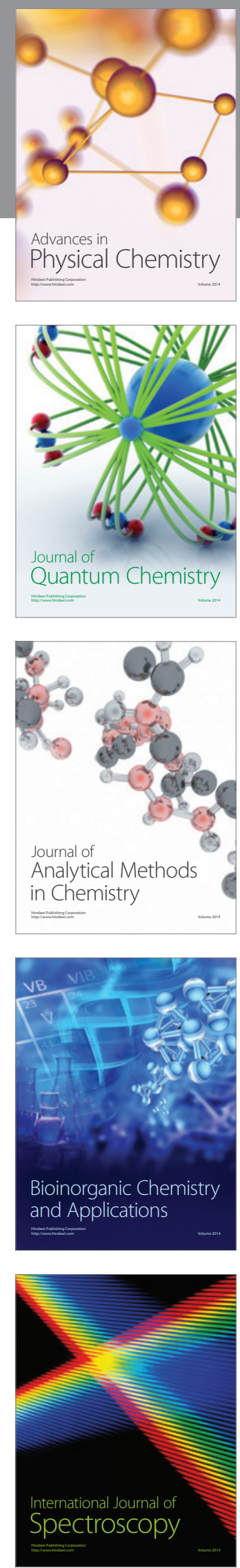